\title{
Foramen magnum schwannoma with an unusual clinical presentation: case report
}

\author{
Koichi Sairyo $^{1}$, Tatsuhiko Henmi ${ }^{1}$ and Hisao Endo ${ }^{2}$ \\ ${ }^{1}$ Department of Orthopedic Surgery, Health Insurance Naruto Hospital; ${ }^{2}$ Endo Orthopedic Hospital, Tokushima, \\ Japan
}

\begin{abstract}
This case report illustrates a patient with a unilateral localized epidural schwannoma at $\mathrm{C} 1-2$ level, showing contralateral spinal cord symptoms and signs. The clinical presentation was compared with the neuroradiological examinations showing an epidural cord tumor at the right $\mathrm{C} 1-\mathrm{C} 2$ level. However, the neurological examination revealed contralateral hemiparesis and ipsilateral hemihypoalgesia, indicating a contralateral Brown-Sequard syndrome. We presumed with this slow growing tumor, contralateral cord involvement may result from counter pressure on the spinal cord, which may be generated by cord deviation and by frequent neck rotation.
\end{abstract}

Keywords: foramen magnum; neoplasm; schwannoma; Brown-Sequard syndrome

\section{Introduction}

Foramen magnum tumors produce many bizarre symptoms, and several reports have made note of the pitfalls in their diagnoses. ${ }^{1-4}$ A unilaterally localized spinal tumor, situated below the pyramidal tract decussation, usually results by presenting with a transverse cord lesion or an ipsilateral BrownSequard syndrome. To our knowledge, there are few reports that the spinal cord is mainly involved contralaterally. In this article, we report a case in which a foramen magnum tumor was situated at the right $\mathrm{C} 1-\mathrm{C} 2$ level with pyramidal tract involvement and clumsiness being more pronounced on the side contralateral to the tumor.

\section{Case report}

A 64-year-old male taxi driver presented to our hospital with a 2-year history of numbness of the right upper and lower extremities and clumsiness and weakness of the left upper and lower extremities. Neurological findings were as follows (Figure 1): diminished sensation of pin-prick below the C5 dermatome level with sacral sparing on the right side and in the left foot, weakness of the left extremities, hyperactive deep tendon reflexes and positive pathological reflexes in the left upper and lower extremities. Plain radiographs showed scalloping of the cranial cortex of the right second cervical lamina. On MR images, a dumbbell-shaped tumor was observed at the $\mathrm{C} 1-\mathrm{C} 2$ level on the right side (Figure 2). Myelographic and CT-myelographic studies demonstrated right-sided

Correspondence: Dr Tatsuhiko Henmi, MD. compression of the cervical spinal cord at the level of C1-C2 (Figure 3).

During a right $\mathrm{C} 1$ hemi-laminectomy, the extradural encapsulated tumor was found to be arising from the right $\mathrm{C} 2$ dorsal root, compressing the spinal cord from the posterolateral aspect at $\mathrm{C} 1-\mathrm{C} 2$ level. The tumor was completely excised with sacrifice of the $\mathrm{C} 2$ root. Histological examination demonstrated that the tumor was a schwannoma. Clumsiness of left extremities improved, but the hypoesthesia did not significantly improve.

\section{Discussion}

Foramen magnum tumors are divided into two anatomical types, craniospinal and spinocranial, as classified by Cushing and Eisenhardt. ${ }^{5}$ Most are meningiomas or schwannomas, and most of the latter are spinocranial in location. ${ }^{3,4}$ The tumor in this patient was a spinocranial schwannoma.

Most fibers of the pyramidal tracts decussate in the region of the lower medulla. ${ }^{6}$ Tumors arising in the upper cervical region therefore produce characteristic motor disturbances, including cruciate paralysis, hemiplegia cruciata and others. In our patient, the tumor was located at the $\mathrm{C} 1-\mathrm{C} 2$ level which should be below the decussation; symptoms of pyramidal tract involvement due to tumors in this location may occur principally in the ipsilateral extremities. Dodge et $a l^{2}$ studied 30 patients with foramen magnum tumors, and found that any motor disturbance was always more pronounced on the side ipsilateral to the tumor. Yasuoka et $a l^{4}$ in the analysis of 57 cases of this type of tumor, found that no patient complained 


\section{(deep tendon reflex)}

biceps

brachioradialis

triceps

patella

Achilles
$R$

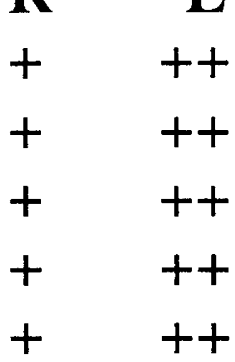

\section{(pathological reflex)}

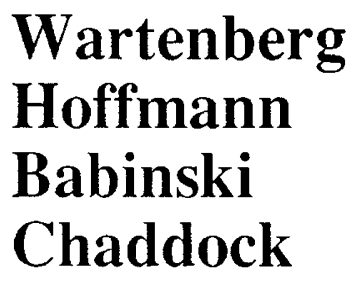

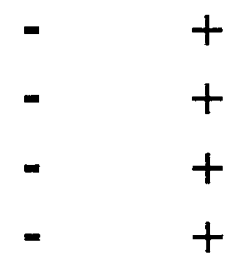

\section{(sensory of pain)}

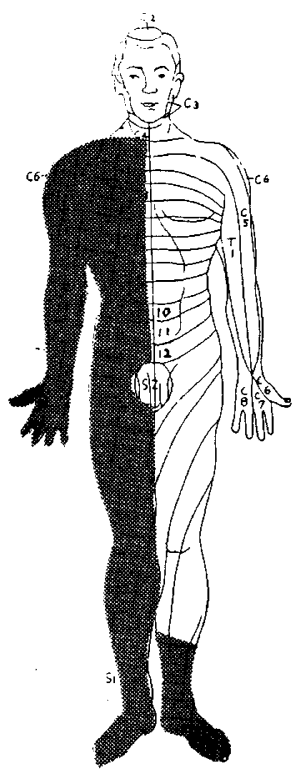

\section{hypoesthesia}

Figure 1 Neurological findings before surgical treatment. These findings indicate that the cervical cord is mainly involved on the left side

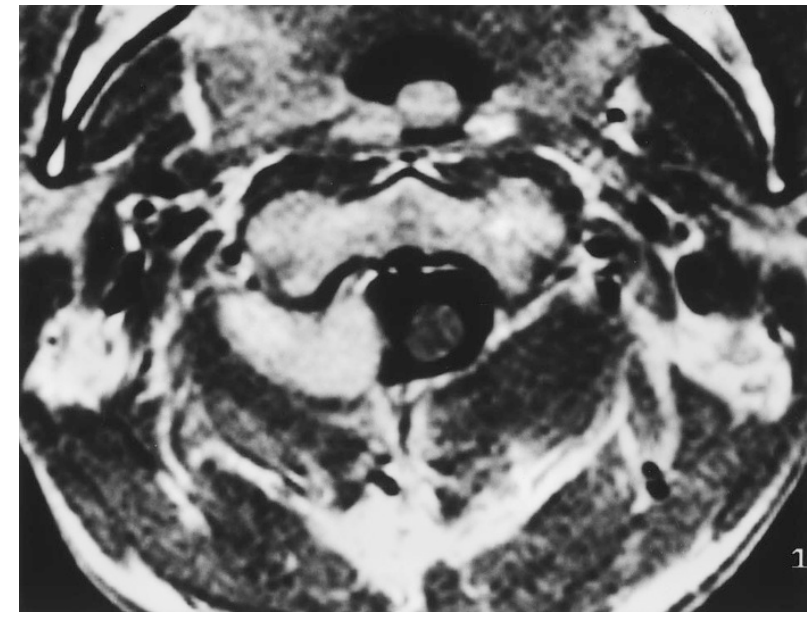

Figure 2 MR axial image (T1 weighted; Tr $500 \mathrm{~ms}$, Te $40 \mathrm{~ms}$ ) demonstrates a dumbbell-shaped tumor at the $\mathrm{C} 1-\mathrm{C} 2$ level on the right side. The tumor is enhanced by Gd-DTPA

of motor disturbance limited to the contralateral side of the body. In our patient, however, weakness and increased deep tendon reflexes were noted in the contralateral extremities. This unusual clinical presentation, the symptoms and signs of which are contrary to those expected may be induced by counter

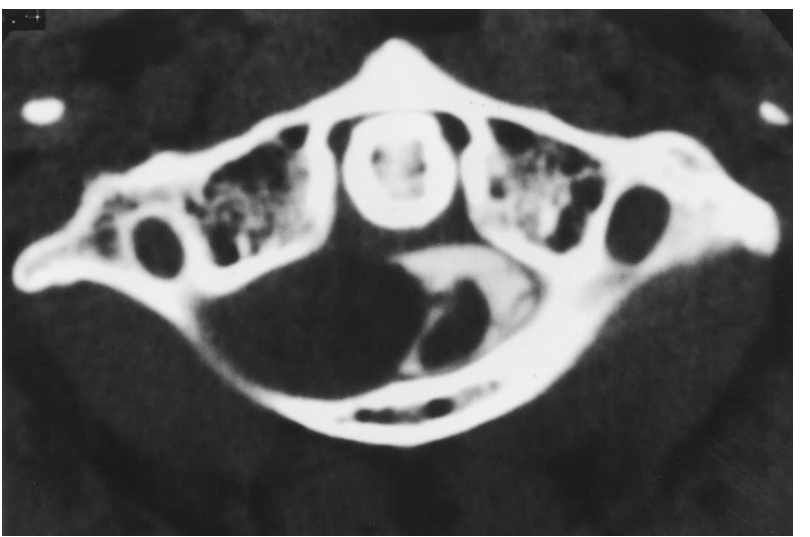

Figure 3 CT-myelogram at $\mathrm{Cl}$ level shows right-sided compression of the cervical spinal cord

pressure of the contralateral lamina during rotational cervical motion or by anatomical anomalies including a low position of the pyramidal decussation and uncrossed pyramidal tract.

The major anatomical movement at $\mathrm{C} 1-\mathrm{C} 2$ level is axial rotation, since approximately half of the maximum axial rotation for the entire neck occurs at this joint. ${ }^{7}$ A tumor situated in the epidural space at this level compresses the spinal cord to the contral- 
ateral side, so that the cord deviates from the rotational center. Compressive forces might involve the spinal cord in contact with the contralateral lamina during rotational motion of the cervical spine. This is the basis for the unexpected findings of signs and symptoms on the side of the body contralateral to the tumor in our patient.

If the pyramidal tract decussates below the level of $\mathrm{C} 1-\mathrm{C} 2$, a contralateral motor disturbance usually occurs as the result of direct compression of the tumor at the $\mathrm{C} 1-\mathrm{C} 2$ level, and an uncrossed pyramidal tract, caused by an enlarged ventral corticospinal tract, may produce contralateral motor disturbances. ${ }^{8}$ These features, however, cannot explain the findings of sensory disturbance on the side ipsilateral to the tumor. Therefore this contrary phenomenon including both motor and sensory disturbances in the present case could not be explained by such anatomical anomalies as a low position of the pyramidal decussation and uncrossed pyramidal tract.

Thus, in the case of a slow growing tumor, contralateral involvement may develop prior to ipsilateral of the spinal cord due to direct compression.

\section{Acknowledgements}

The authors thank Dr S Katoh, Department of Orthopedic Surgery, School of Medicine, The University of Tokushima, for his critical review of this manuscript.

\section{References}

1 Cohen L, Macrae D. Tumors in the region of the foramen magnum. J Neurosurg 1962; 19: $462-469$.

2 Dodge HW, Love G, Gottlieb VM. Benign tumors at the foramen magnum, surgical considerations. J Neurosurg 1956; 13: $603-$ 617.

3 Meyer FB, Ebersold MJ, Reese DF. Benign tumors of the foramen magnum. J Neurosurg 1984; 61: 136-142.

4 Yasuoka S, Okazaki H, Daube JR, MacCarty CS. Foramen magnum tumors. J Neurosurg 1978; 49: $828-838$.

5 Cushing H, Eisenhardt L. Their classification, regional behavior life history, and surgical end results. Springfield, III., Charles C Thomas, 1938.

6 Baker AB. Clinical neurology. 2nd edn. New York: Harper \& Row, 1965: p 1537.

7 Frymoyer JW. The adult spine, principles and practice. New York: Raven Press, 1991: p937.

8 Baker AB. Clinical neurology 2nd edn. New York: Harper \& Row, 1965: p 1973. 